\title{
Customer relationship management architecture in the pharmaceutical industry
}

\section{Rainer Alt*, Hubert Österle and Thomas Puschmann}

Institute of Information Management, University of St. Gallen, St. Gallen, Switzerland

E-mail: rainer.alt@unisg.ch

E-mail: hubert.oesterle@unisg.ch

E-mail: thomas.puschmann@unisg.ch

*Corresponding author

\section{Vladimir Barak and Thomas Huber}

F. Hoffmann-La Roche, Basel, Switzerland

E-mail: vladimir.barak@roche.com

E-mail: thomas.huber.th3@roche.com

\begin{abstract}
The pharmaceutical industry is undergoing a fundamental transformation. Institutional regulations that have been in place for decades are being removed and competitive pressures on various levels force pharmaceutical companies to adopt customer-oriented strategies. Information technology is an important enabler to improve the interaction with key customer segments, such as physicians, and patients. This research presents a framework that has been elaborated in cooperation with nine companies and applied at a major pharmaceutical company for the development of process portals. These portals include services that support the processes of specific customer segments from internal and external sources. The architecture shows the implications of process portals on a strategic, a process and a systems level.
\end{abstract}

Keywords: customer process; customer relationship management-architecture; pharmaceutical industry; portal; web services.

Reference to this paper should be made as follows: Alt, R., Österle, H., Puschmann, T., Barak, V. and Huber, T. (2003) 'Customer relationship management architecture in the pharmaceutical industry', Int. J. Healthcare Technology and Management, Vol. 5, Nos. 3/4/5, pp.296-314.

Biographical notes: Rainer Alt is a Project Manager and a Senior Lecturer at the Institute of Information Management, University of St. Gallen, Switzerland. He received his master's degree in business administration from the University of Erlangen-Nuremberg and his $\mathrm{PhD}$ from the University of St. Gallen. Before assuming his current position, he was with Roland Berger Strategy Consultants in Germany. 
Hubert Österle is Professor of information management, Director of the Institute of Information Management at the University of St. Gallen and Chief Technology Officer of IMG AG. He received his master's degree in business management at the Universities of Innsbruck and Linz, his PhD at the University of Erlangen-Nuremberg and qualified as Professor at the University of Dortmund.

Thomas Puschmann is a Project Manager at the Institute of Information Management, University of St. Gallen, Switzerland. He received his master's degree in management sciences from the University of Konstanz and his PhD from the University of St. Gallen. His research areas are business networking, customer relationship management and portals.

Vladimir Barak is Global Head of Sales \& Marketing Information Management at F. Hoffmann-La Roche Ltd. He received his master's degree in computer sciences from the Moscow Technology Institute and his $\mathrm{PhD}$ from the University of Mainz. In his position, he is currently establishing a global IM function for sales and marketing focusing on global coordination, cross-site aspects and local support (CRM, sales processes, e-business opportunities, internet) $\mathrm{He}$ is member of the Informatics Management Team (IMT) of the Pharma Division.

Thomas Huber is Sales \& Marketing Information Manager at F. Hoffmann-La Roche Ltd. He received his master degree in business administration and his $\mathrm{PhD}$ in information management from the University of St. Gallen, Switzerland. In his current position he is responsible for the governance of large affiliates in CRM and Siebel. He is also the Project Manager of the Siebel implementation in Germany and chairs the Global Siebel User Group of Roche.

\section{Introduction}

Although the orientation on customer requirements is not new and has been an important element in business reengineering philosophies, companies in many industries are still product focused. For example, the pharma(ceutical) industry mainly relies on the development and marketing of high-volume products ('blockbusters') to physicians, hospitals, and wholesalers [1,2]. In view of an increasingly competitive marketplace this strategy is no longer sufficient. Among the profound changes taking place in this industry is the upcoming direct sale of prescription drugs, increasingly well-informed patients, the growing number of cost reductions of governments and health insurance providers as well as new internet-based initiatives dubbed 'e-healthcare'-sites.

Compared to other industries, such as banking or high tech, pharma companies are only at the beginning of systematically managing relationships to customers [3]. Kalustain et al. [4] observed that customer relationship management (CRM) 'has become a pharma buzzword, but few companies actually practice it'. Information technology (IT) and especially the internet is an important enabler for customer orientation in this industry. As Lin and Huaring [5] point out, it improves the circulation of product and disease information to the customer; in supporting campaigns and clinical trials it is an additional marketing tool, and it is a channel to 
provide more value to customers. The opportunity to establish efficient direct contact with customers has not only been recognised by pharma companies, but also by other actors in the pharma industry, such as pharmacies, as well as by start-ups such as online pharmacies.

The question is how established ('brick-and mortar') pharma companies position themselves in the new electronic marketplace and how they use internet technologies to sustain their core processes. Following Porter [6], the internet is conceived as an electronic interaction channel to customers which complements traditional channels (e.g. sales force, call centres). Although the internet is an important enabler for improving the interaction with different customer segments - patients in particular - an overall CRM strategy is required to avoid failure which has reportedly been high in many companies [7].

The research presents an architecture framework that has been developed in the 'Competence Center Business Networking', a multilateral project with nine international companies from 2000 and 2002 at the University of St. Gallen, Switzerland. Based on established principles from business reengineering, an architecture was developed for systematically analysing customer relationships using well-proven techniques from business engineering. In applying the architecture at Pharma AG, one of the largest pharma companies worldwide, this research follows the tradition of action research where the researcher is directly involved in the project work [8].

\section{Customer orientation in the pharma industry}

\subsection{Challenges for pharma companies}

Investing in developing new products and enhancing customer relationships are considered as the main strategies in the changing pharma marketplace [9]. Whereas product development has traditionally received much attention, the conceptualisation and implementation of customer orientation is a new topic for pharma companies. Among the main drivers for a customer oriented strategy are:

- Demanding healthcare customers. More competition increases the negotiation power of patients who demand more value at lower prices and more freedom of choice regarding healthcare providers [10]. These patients increasingly influence the choice of drugs and reduce the physician's traditional role as a decision-maker. Considering means to influence patient satisfaction becomes more important but requires a profound knowledge of customer needs which hardly exist among pharma companies today.

- Restricted access to physicians. The number of visits of the pharma sales reps to present products ('detailing') is set to decrease due to regulation in various European countries and the doctors' falling acceptance. At the same time, the number of sales reps in the 40 largest pharma companies has doubled while prescriptions have only grown by $15 \%$ [11]. Pharma companies not only need more efficiency in their traditional sales force, but must also exploit new interaction channels with this key customer segment. 
- Increasing cost pressure. To contain exploding health costs, governments are exerting increasing pressure on the prices of pharma products. At the same time, parallel imports from low-cost countries and the growing competition from generic drug manufacturers are eroding margins. Many pharma companies have therefore decided to optimise their sales strategies by introducing key account management structures.

- Regulation. In the European Union, Council Directive 92/28/EEC of March 31, 1992, prohibits the advertising of medical products for human use among end-users. The US removed these restriction in 1997 and similar developments are now expected for Europe [12]. Pharma companies addressing the European market need to include direct sales and marketing in their strategies since online pharmacies, procurement platforms or health portals may intermediate the pharma company's customer access.

\subsection{Limitations of traditional sales and marketing}

The sales organisation of many pharma companies is geared towards physicians, hospitals, wholesalers, pharmacies, and end customers, i.e. patients. However, the latter are currently not addressed due to regulation and complex relationships between end customers and the pharma companies. While manufacturers in other industries deal with the end customer direct, pharma companies are entwined in a web of relationships with physicians (who prescribe but do not buy medicines), pharmacies and hospitals (who buy but do not prescribe) and patients (who buy but do not decide on products). Pharma companies have established three different system to support the interaction with these customer segments:

- systems for Territory Management (TMS) or Sales Force Automation (SFA) have been in operation for some time for supporting the regular visits of sales reps to physicians

- Key Account Management (KAM) is an enhanced form of TMS, where dedicated key account managers look after major customers such as hospitals, wholesalers and hospital buying syndicates

- call centres and portal applications are emerging in certain countries for physicians as well as for patients. Examples are portals for specific diseases (e.g. oncology) or products (e.g. Aspirin).

Figure 1 shows the evolution of these systems at Pharma AG and the goal to develop an integrated architecture which overcomes today's shortcomings. Customer information is neither systematically gathered and communicated between the local marketing divisions, nor are interactions with customers on portals or call centres coordinated with the existing KAM or TMS. This impedes the identification of customer segments (e.g. chronically ill patients), the development of required additional services, and the usage of up-/cross-selling. 
Figure 1 Customer segments and channels in the pharma industry

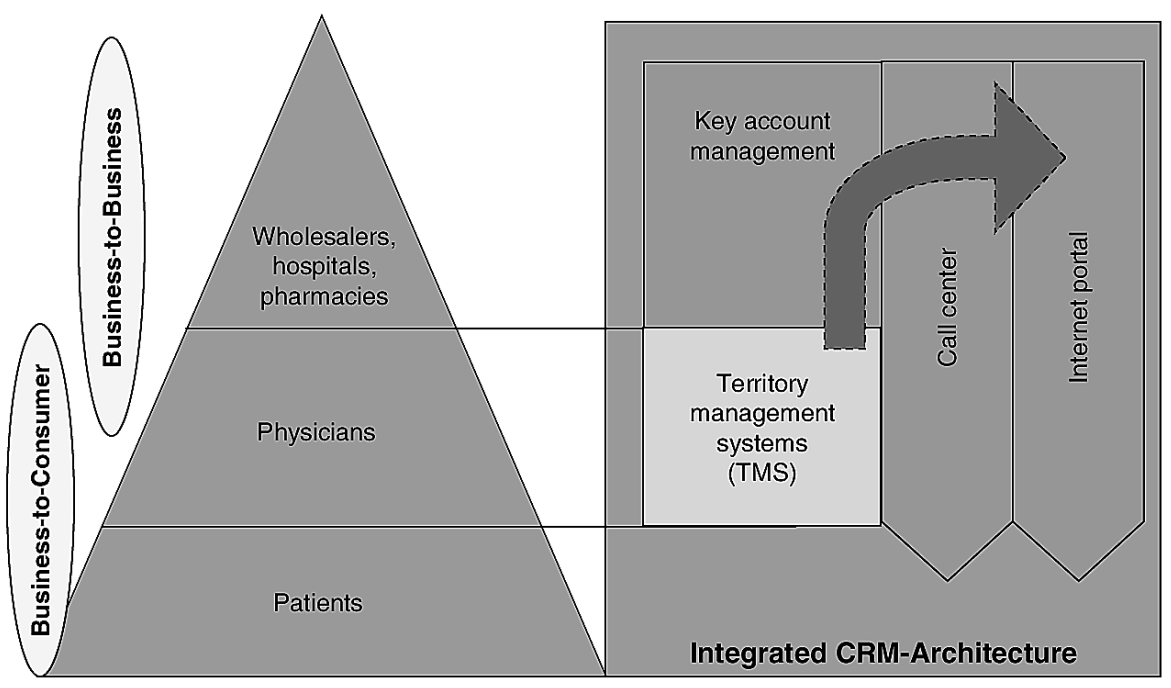

\subsection{Potentials of integrated CRM}

An integrated CRM-approach provides electronic support for the key customer oriented processes (sales, marketing, service) across various interaction channels $[13,14]$. Based on a cross-functional usage of processes and customer information, CRM leads to potentials in three areas for pharma companies:

- Enhanced information about customers allows for a systematic segmentation of customers and a differentiated approach of various groups. For example, patients may be segmented depending on their disease (see Figure 2). Chronic disease patients are long-term patients who invest time in understanding their disease as well as possible medication alternatives. Establishing personalised bilateral relationships is a promising strategy for this segment. On the other hand, patients with acute diseases are mainly interested in standard information on combating symptoms to overcome their disease. A mass marketing approach with less investment in individual relationships is adequate here. However, a pharma companies' CRM activities should aim at expanding the needs of this segment, e.g. from short-term illness to long-term wellness.

- Based on a fine-grained segmentation pharma companies are able to offer value added services that go beyond the selling of drugs and 'blockbusters' (see

Figure 3). These services cover various stages of the customer's life cycle [15] and are specific to customer segments. For example, chronic bronchitis patients could be provided with in-depth information on cortisone and antibiotics as well as on various drugs which are necessary during the course of their illness. Patients with acute diseases could be offered standard drug information to combat high temperatures, chest pains or coughing and general prevention advice. 
- Enhanced revenues by recognising interdependencies between the pharma company's various products. An example is integrated customer knowledge across a pharma company's diagnostics and pharma divisions. A physician who works with diabetes patients and uses a pharma company's equipment for blood analysis can also be offered drugs for preventing weight problems ('cross-selling'). The same applies within individual product lines to support sales of a higher-grade product ('up-selling').

Figure 2 Segmentation of patients

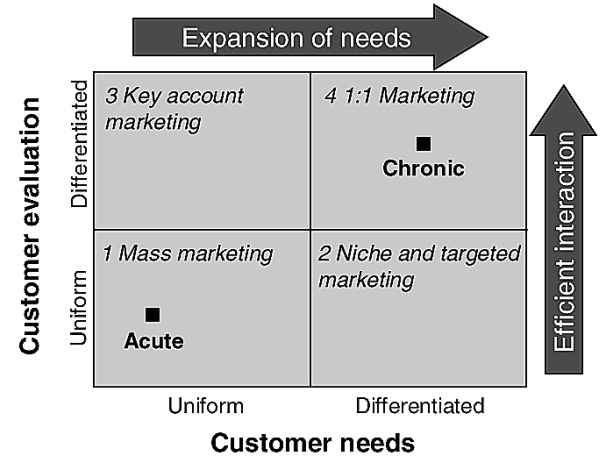

Figure 3 Evolution from product to value added services

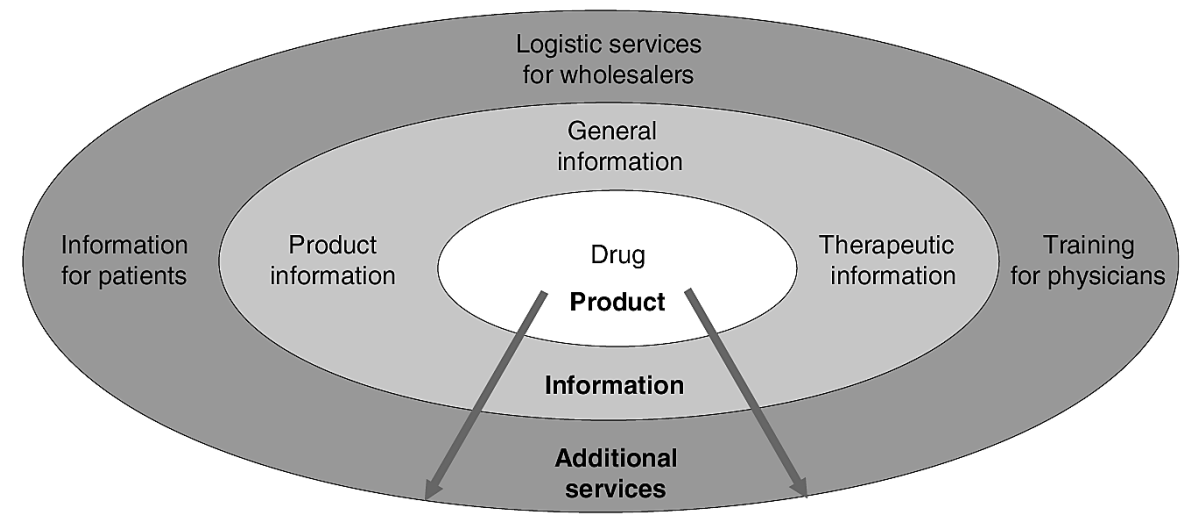

\section{Development of a CRM architecture}

Shaping an integrated CRM architecture needs to take into account the strategic changes in the marketplace, the processes which provide services to the customer, as well as the enabling information systems. These aspects are systematically covered in the established business process redesign methodologies. For example, business engineering recognises the process as the link between strategy and systems development [16]. However, these methods have neither been explicitly applied for customer oriented nor for interorganisational solutions. 
A first step towards addressing both shortcomings is presented in the following CRM architecture which builds on the mentioned business engineering approach. In a top-down approach, a business architecture provides the frame for understanding the transformation of the sales channels within the industry (Section 3.1). The process architecture develops the main design elements for shaping customer-oriented services (Section 3.2). Finally, the systems architecture structures the supporting applications (Section 3.3).

\subsection{Business architecture}

The Pharma AG is a multinational company headquartered in Basel, Switzerland and is among the ten biggest pharmaceutical companies in the world. The developments in the pharma industry as described in Section 2 initiated an evaluation and positioning process at Pharma AG. Since significant changes were expected in all downstream (i.e. customer facing) activities, upstream contacts were not within the scope of this project. Among the main goals were to:

- assess the possibilities of the internet for the interaction with key customer segments

- positioning towards initiatives from other players in the industry and third parties

- to derive measures for the forthcoming years. The analysis at Pharma AG was limited to Europe since the greatest changes were expected here.

\subsubsection{Customer segmentation}

On a strategic level customer orientation requires a sound understanding of all downstream interaction channels. As a basis the existing business architecture in the pharma industry was developed (see Figure 4) with Pharma AG's internal departments as well as the customer segments along the various interaction channels (business-to-business, business-to-doctor, business-to-consumer, and business-to-government) in Europe [17].

- Physicians are currently the most important customer segment as they possess the authority as well as the product and professional know-how to decide on the prescribed products. They are the main contact group of a pharma company's sales force which leads to an estimated cost of EUR 1000 for a visit of approximately 9 minutes [18].

- Hospitals are high-volume customers for medicines. For example, the hospitals in Switzerland purchased $20.7 \%$ of prescription medicines in 2000 [19]. Although product decisions are still influenced by physicians, hospitals increasingly employ professional procurement staff that exerts competitive pressures on pharma companies.

- Wholesalers distribute medicines to pharmacies. They are not actual customers of pharma companies but rather a distribution channel. However, they are important players in the industry since the three largest wholesalers already operate throughout Europe. Consolidation is expected to grow further towards downstream integration of pharmacies and hospitals. 
- Pharmacies sell medicines to patients on prescription basis. They are the actual vendors of drugs. For example, pharmacies sold $55.6 \%$ of all prescription medicines in Switzerland [19]. Pharmacies buy their products from wholesalers and do not source directly from pharma companies.

- Patients are the pharma companies' end customers. They are increasingly self-educated, more sceptical towards doctors and see the function of pharma products not only as being to treat illnesses but also to prevent them and prolong health. Pharma companies aim at providing information which may influence the choice of drugs.

- Patient groups offer information regarding specific illnesses and influence developments in the industry. An interest group of patients, government and industry representatives, for example, was effective in securing approval of Herceptin (a drug used against breast cancer) by promoting the drug to gain faster approval by the Food and Drug Administration [20]. Pharma companies aim at addressing patient groups with suitable services and information at the right moment in time.

Figure 4 Traditional business architecture in the pharma industry

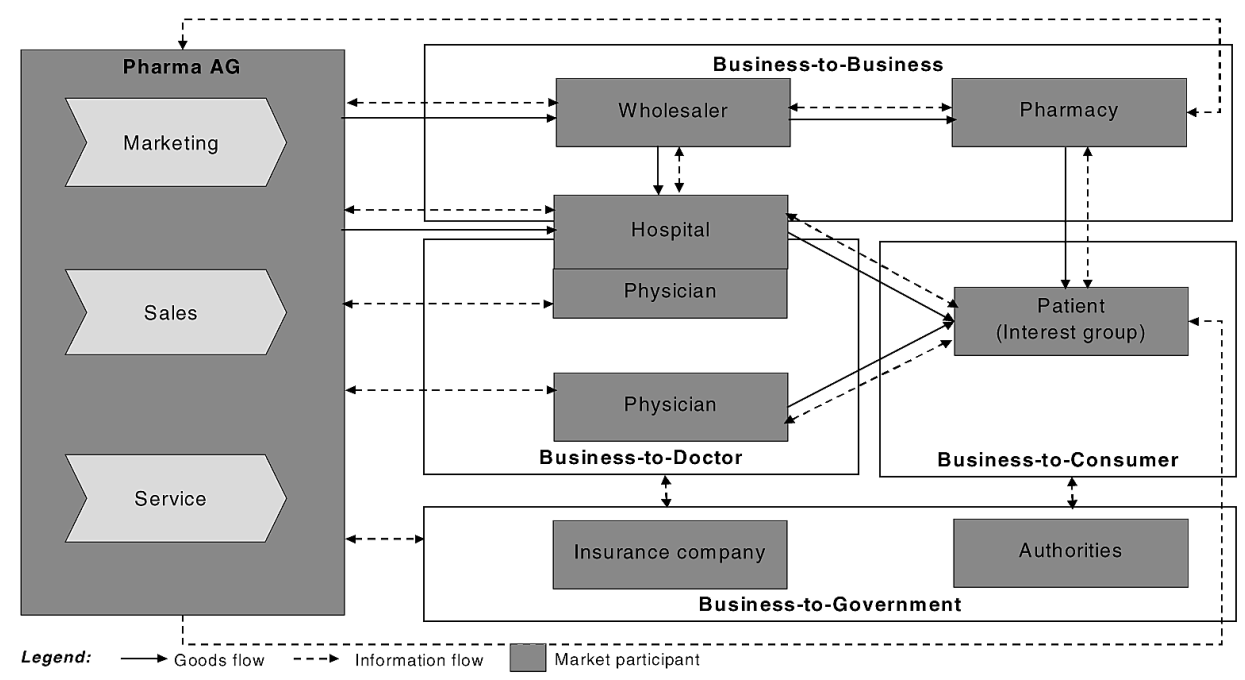

\subsubsection{Changes in the business architecture}

During the internet hype the pharma industry has seen a proliferation of websites, portals and marketplaces. Portals are websites that personalise and integrate information on products and services from different vendors and applications. While portals aim at differentiation by bundling information to provide a maximum coverage of customer processes, marketplaces (n:m portals) focus on achieving cost leadership by streamlining transactions among competing suppliers using market mechanisms (e.g. auctions). The business architecture shows the activities of the various actors in the pharma industry. Pharma companies have established solutions to five customer segments (see 1 in Figure 5): 
- Patients receive information and services concerning diseases or therapies. Examples are chat rooms for specific patient groups or tips on therapies [5].

- Hospitals are offered catalogues for procurement of pharma products. Although proprietary systems have been developed, hospitals prefer multi-vendor solutions. Pharma companies have jointly initiated n:m portals such as Vamedis [21].

- Physicians receive information on drugs, treatments, current research as well as support in their operational processes and in training. Several companies have started pilots for interactive product presentations ('eDetailing') [11]. An example is $\mathrm{MyDoc}$ Online from Aventis.

- Pharmacies and wholesalers receive only little information from pharma companies. Pharmacies are traditionally the wholesaler's customer and wholesalers have established their own complex ordering systems.

Figure 5 Future business architecture in the pharma industry

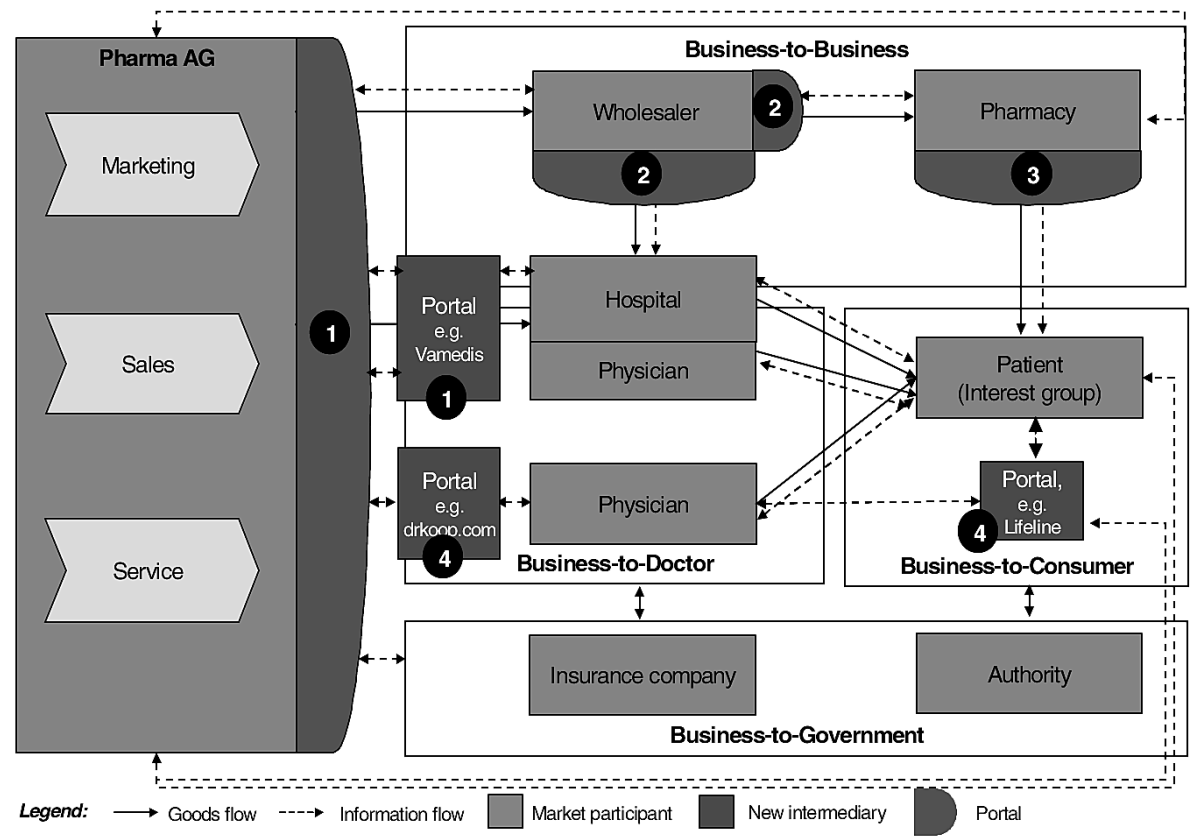

Wholesaler portals (see area 2 in Figure 5) support electronic ordering and the purchase of drugs between multiple pharma companies and pharmacies. Often they build upon a wholesaler's established electronic ordering system. 
Two types of developments can be observed in the pharmacy area (see 3 in Figure 5). First, pharmacies establish websites that include electronic chats with the pharmacist or drug ordering services. The latter enable patients to enter the required drug, fax the prescription and collect the product in the physical store. Second, virtual pharmacies in the US and the UK offer electronic catalogues, order entry and prescription handling. Among the remaining examples are drugstore.com or cvs.com.

New information providers (see 4 in Figure 5) include telemedical services for exchanging multimedia data (e.g. reports, X-rays, insurance number, etc.) between physicians and patients [22]. Other portals provide in-depth knowledge on drugs and healthcare (e.g. drkoop.com, webmd.com) or offer e-detailing services (e.g. iPhysicianNet). Pharma companies have also established disease portals for direct contact to end customers. Among the examples are lillydirect.com for oncologists by Eli Lilly, raacademy.com for patients with rheumatoid arthritis or ibreathe.com for asthma patients by GlaxoSmithKline.

When Pharma AG evaluated the implications on their business architecture in 2001, the changes were considered complementary to their existing strategies [23,24]. Pharma AG decided to achieve state-of-the-art regarding their websites (e.g. uniform layout worldwide, consistent product information), to maintain parity in the area of online pharmacies and downstream marketplaces (i.e. act upon strategic necessity), and to develop competitive advantages by establishing portals to increase differentiation in specific customer segments. In a number of workshops with Pharma AG's country organisations, the existing and expected importance of the customer segments was evaluated. As Figure 6 suggests, patients and wholesalers should receive more attention in the future. However, physicians remain the most important customer segment for pharmaceutical companies.

Figure 6 Importance of customer segments at Pharma AG

Today

importance

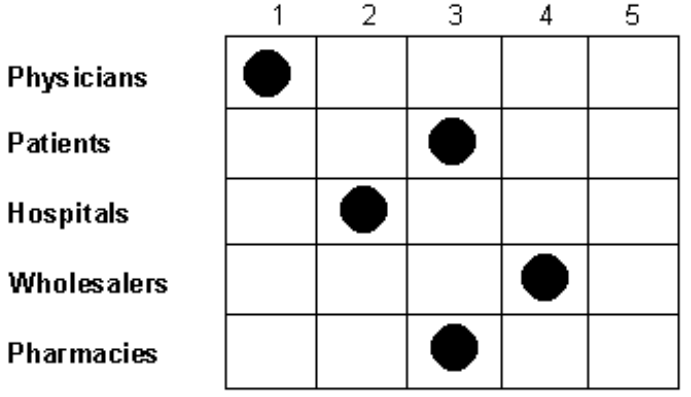

Future

importance

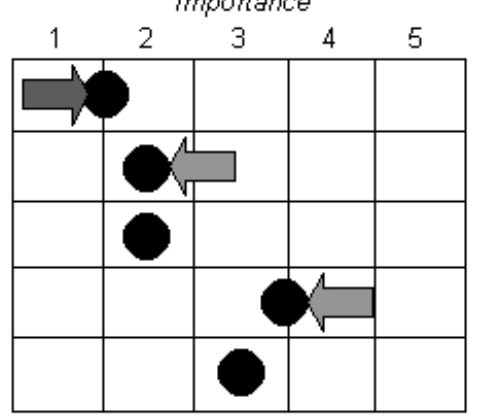

$1=$ Most important, $5=$ Least important 


\subsection{Process architecture}

\subsubsection{Customer process analysis}

The next step for developing customer orientation is the identification of customer processes for each customer segment. The customer process encompasses all the tasks which customers go through in order to satisfy their needs [25]. To analyse customer processes Pharma AG conducted several internal workshops and customer surveys in six European countries with an average of ten sales and marketing representatives. Three hospitals, two buying syndicates and two wholesalers took part in the external survey. Pharma AG analysed the customer processes of the five main customer segments and derived possible portal services (see Figure 7):

- The customer process of patients evolves around the prevention and treatment of an illness. The sub-processes may differ in length and show that healthy persons can also be customers of pharma companies (prevent).

- The physician's process focuses on providing advice and prescribing drugs to patients. Supporting processes are: knowledge management, i.e. archiving of information from medical journals or newsletters; professional development, i.e. continuous medical education (CME) with online seminars etc.; patient data management, i.e. the storage of patient data and their medical histories; and back-office, i.e. all management activities associated with treatment.

- Hospital pharmacies have an emphasis on warehouse management. The customer process starts with observing medical developments and searching information on sales figures, approval requirements and side effects of drugs. After checking the inventory and comparing terms of delivery, the hospital pharmacist initiates a purchase order, the goods and the invoice are checked upon receipt, and the goods are assigned to the warehouse.

- Compared to hospital pharmacies, 'independent' pharmacies are more sales-driven than logistics-driven. Dispensing drugs and advising customers is important here. Necessary support processes are prescription handling and ordering.

- The wholesaler's process resembles the hospital's customer process in general. Purchasing managers search for product information, new products on the market and data on drugs such as the size of shipping units, the number of tablets or capsules per pack. Terms such as payment and delivery dates are agreed with the pharma companies depending on local reference prices [26]. 
Figure 7 Customer processes with portal services at Pharma AG

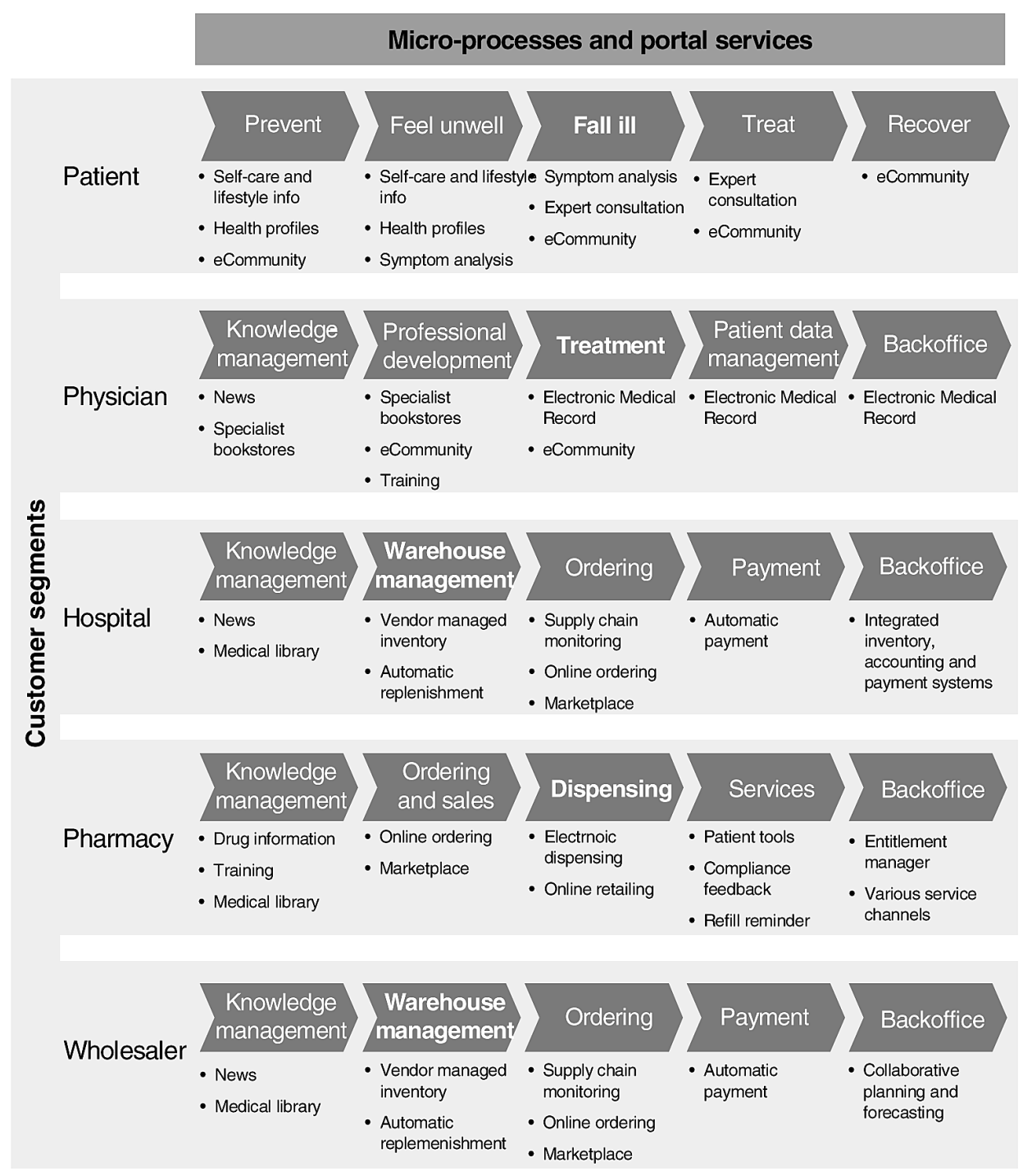

The customer processes illustrate the different competitive strategies as described in the business architecture. Cost leadership is especially strong with hospitals, pharmacies and wholesalers which aim at increasing operational efficiency. The services offered to physicians and patients are more geared towards differentiation via tailored information and personalised interaction. 


\subsubsection{Portal process architecture}

In a second step Pharma AG developed the process architecture and analysed how the individual services within the customer processes could be integrated in a portal that is integrated with the main CRM processes (see Figure 9):

- Marketing mainly provides services for pre-transaction activities. Pharma AG's marketing is organised according to the company's therapeutic fields. Although a distinction is made between the customer segments 'hospitals' and 'physicians' at the top level, all activities one level further down are linked to specific products. Marketing defines all customer information to be collected by the sales force.

- Like marketing, sales is organised according to hospitals and physicians, and product lines at the next level. To avoid that different sales reps visit the same customers, Pharma AG has appointed key account managers who are not responsible for the success of individual products but for customer profitability. The CRM system provides information across product lines (see Figure 8).

- Call centres are a major element in Pharma AG's service area. A single telephone number (contact point) has been established for questions regarding products. Calls are automatically routed to the person or department concerned, depending on the call and the type of support required. The CRM system supports call centre staff with detailed, up-to-date customer information.

Figure 8 Organisation of territory management and key account management
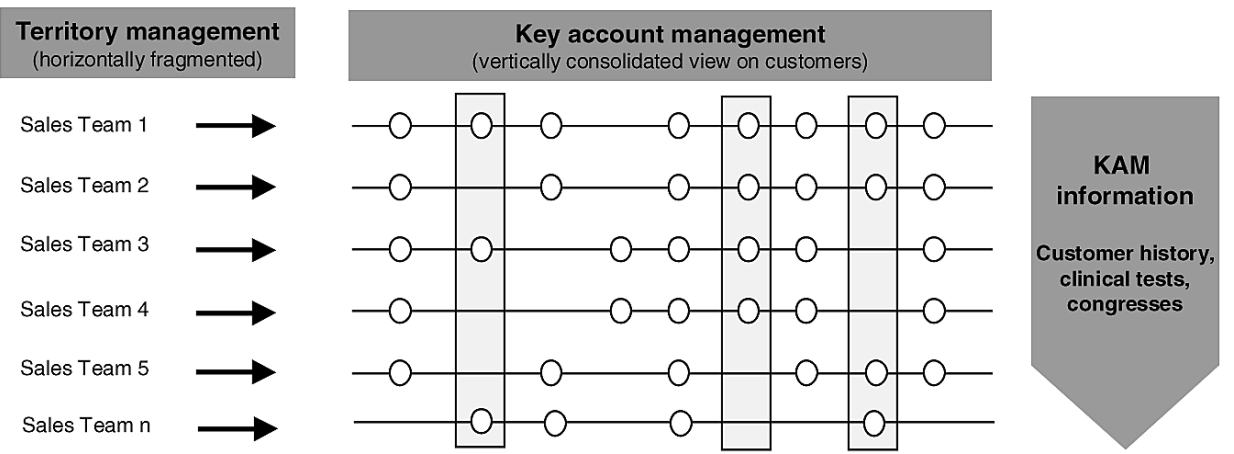

Legend: $\bigcirc$ Customer unit supported by sales team 
The portal architecture in Figure 9 also includes the services of external providers. These web services offer electronic services for specific highly standardised tasks and are charged on a time or usage basis $[27,28]$. They enable a pharma company to focus on critical content and services. Web services have emerged for specific tasks in business processes, for horizontal tasks that may be applied in various business processes (content and transaction services), for the consolidation, the unique retrieval, and the automatic routing of information (integration services), as well as for network operation (IT operation services) [23]. Figure 10 shows examples of web services which were considered important in Pharma AG's portal architecture.

Figure 9 Portal process architecture for customer segment 'Patients'

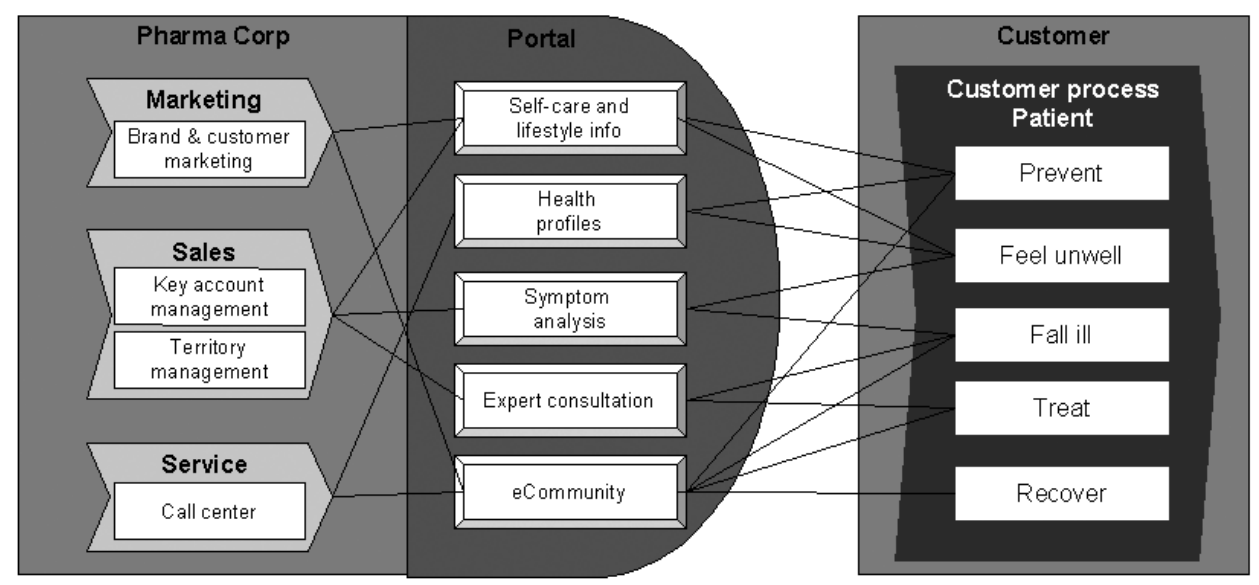

\begin{tabular}{|c|c|c|c|}
\hline \multicolumn{4}{|c|}{ Business Collaboration Infrastructure } \\
\hline $\begin{array}{l}\text { Business Process } \\
\text { - Billing and payment } \\
\text { - Order tracking } \\
\text { - Cross-and upselling } \\
\text { - Customer profiling }\end{array}$ & $\begin{array}{l}\text { Content \& Transaction } \\
\text { - Community management } \\
\text { - Management reporting } \\
\text { - Product catalogs } \\
\text { - Question/Answer mgmt. }\end{array}$ & $\begin{array}{l}\text { Integration } \\
\text { - ContentiData accumulation } \\
\text { - Business directories } \\
\text { - Catalog management } \\
\text { - Subscriber registration }\end{array}$ & $\begin{array}{l}\text { IT-Operation } \\
\text { - Security (Authorization, } \\
\text { authentication) } \\
\text { - Webpage performance mgmt } \\
\text { - Feasibility assessment }\end{array}$ \\
\hline
\end{tabular}

Web services may also be pre-configured into an infrastructure. For example, procurement, payment, logistics, directory, and security services are offered by a third party provider, e.g. an electronic marketplace such as Vamedis. Pharma AG is planning to integrate selected web services bilaterally and has evaluated services that support the differentiation approach required in process portals for the customer segments 'patients' and 'physicians' (see Figure 10). Cost leadership strategies for customer segments 'hospital' or 'wholesaler' require different configurations of web services. 
Figure 10 Web services for patient and physician portals

\begin{tabular}{|c|c|c|c|c|c|c|c|c|c|c|}
\hline \multirow[b]{2}{*}{ Web service } & \multicolumn{5}{|c|}{$\begin{array}{l}\text { Customer process } \\
\text { 'Patient' }\end{array}$} & \multicolumn{5}{|c|}{$\begin{array}{l}\text { Customer process } \\
\text { 'Physician' }\end{array}$} \\
\hline & $\begin{array}{l}\overrightarrow{\bar{D}} \\
\overrightarrow{0} \\
\overrightarrow{0}\end{array}$ & 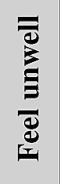 & 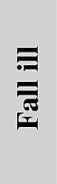 & E & 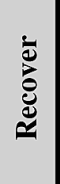 & 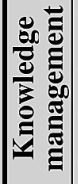 & 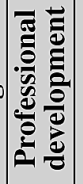 & 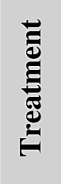 & 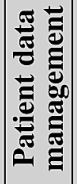 & 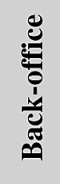 \\
\hline \multicolumn{11}{|l|}{ Business process services } \\
\hline \multicolumn{11}{|l|}{$\begin{array}{l}\text { Online prescriptions } \\
\text { (http://www.rxhub.net) }\end{array}$} \\
\hline \multicolumn{11}{|l|}{$\begin{array}{l}\text { Appointment service } \\
\text { (http://www.healinx.com) }\end{array}$} \\
\hline \multicolumn{11}{|l|}{$\begin{array}{l}\text { Immediate medical assistance } \\
\text { (http://www.getwellness.ch) }\end{array}$} \\
\hline \multicolumn{11}{|l|}{$\begin{array}{l}\text { Online visit to the doctor's } \\
\text { (http://www.healinx.com) }\end{array}$} \\
\hline \multicolumn{11}{|l|}{$\begin{array}{l}\text { Professional training (x-rays) } \\
\text { (http://www.radeikon.com) }\end{array}$} \\
\hline \multicolumn{11}{|l|}{$\begin{array}{l}\text { Online hospital registration } \\
\text { (http://optimizer.sanalink.com) }\end{array}$} \\
\hline \multicolumn{11}{|l|}{$\begin{array}{l}\text { Continuous medical education } \\
\text { (http://www.medscape.com) }\end{array}$} \\
\hline \multicolumn{11}{|l|}{ Content \& transaction services } \\
\hline \multicolumn{11}{|l|}{$\begin{array}{l}\text { Health information } \\
\text { (http://www.pharmavista.net) }\end{array}$} \\
\hline \multicolumn{11}{|l|}{$\begin{array}{l}\text { Discussion forums } \\
\text { (http://www.getwellness.ch) }\end{array}$} \\
\hline \multicolumn{11}{|l|}{$\begin{array}{l}\text { Patient dossier exchange } \\
\text { (http://optimizer.sanalink.com) }\end{array}$} \\
\hline \multicolumn{11}{|l|}{$\begin{array}{l}\text { Personal health data record } \\
\text { (http://www.webmd.com) }\end{array}$} \\
\hline \multicolumn{11}{|l|}{$\begin{array}{l}\text { Self-care tips } \\
\text { (http://www.webmd.com) }\end{array}$} \\
\hline \multicolumn{11}{|l|}{$\begin{array}{l}\text { Journal service } \\
\text { (http://www.medscape.com) }\end{array}$} \\
\hline \multicolumn{11}{|l|}{$\begin{array}{l}\text { Communities } \\
\text { (http://www.netdoktor.de) }\end{array}$} \\
\hline \multicolumn{11}{|l|}{$\begin{array}{l}\text { Drug catalog } \\
\text { (http://www.drugstore.com) }\end{array}$} \\
\hline \multicolumn{11}{|l|}{$\begin{array}{l}\text { Drug warnings } \\
\text { (http://www.drugstore.com) }\end{array}$} \\
\hline \multicolumn{11}{|l|}{$\begin{array}{l}\text { Drug check } \\
\text { (http://www.gesundheitscout24.de) }\end{array}$} \\
\hline \multicolumn{11}{|l|}{ Integration services } \\
\hline \multicolumn{11}{|l|}{$\begin{array}{l}\text { Dictionaries of illnesses/drugs } \\
\text { (http://www.netdoktor.de) }\end{array}$} \\
\hline \multicolumn{11}{|l|}{$\begin{array}{l}\text { Physician and therapist search } \\
\text { (http://www.gesundheitscout24.de) }\end{array}$} \\
\hline $\begin{array}{l}\text { Directories } \\
\text { (http://www.medizin.ch) }\end{array}$ & & & & & & & & & & \\
\hline
\end{tabular}




\subsection{System architecture}

The system architecture implements the process architecture regarding:

- the applications which provide the functionality for the portal and the CRM processes

- the integration solution which provides semantic and syntactical compatibility for homogenised customer data

- the technical infrastructure for the secure technical connectivity. Since the infrastructure architecture uses standard internet technology it is not elaborated here.

As a global company with strong local country divisions Pharma AG decided to develop a highly decentralised system architecture (see Figure 11). To avoid incompatible customer data and the implementation of multiple different systems, corporate guidelines determine for each country:

- The application architecture which reflects the functional requirements in the processes marketing (analytical and mailing functionalities), sales (functionalities for planning and reporting of visits, expense, sample and congress management), and service (functionalities for call centres, e.g. automatic call recognition). The ERP application is used for product management, ordering, and sales; the CRM application for call centre, sales force, and marketing purposes.

- The customer information platform (CIP) as a key element of the integration architecture. CIP defines a customer data model and methods to integrate local and corporate customer data. Both CRM and ERP supply and use data from the CIP which consists of a data warehouse and master data management solution (MDM). The data warehouse integrates data from various heterogeneous systems and consolidates data for reporting purposes. MDM harmonises the different field names and customer ID numbers into a corporate standard.

- The choice of system vendors which was limited to SAP in the ERP area and Siebel or Update.com in the CRM area. While large countries use Siebel, smaller countries use of Update's Marketing Manager. Other CRM systems will be replaced. Standard configurations have also been developed for portals where a solution from BEA/ATG has been selected. 
Figure 11 System architecture at Pharma AG

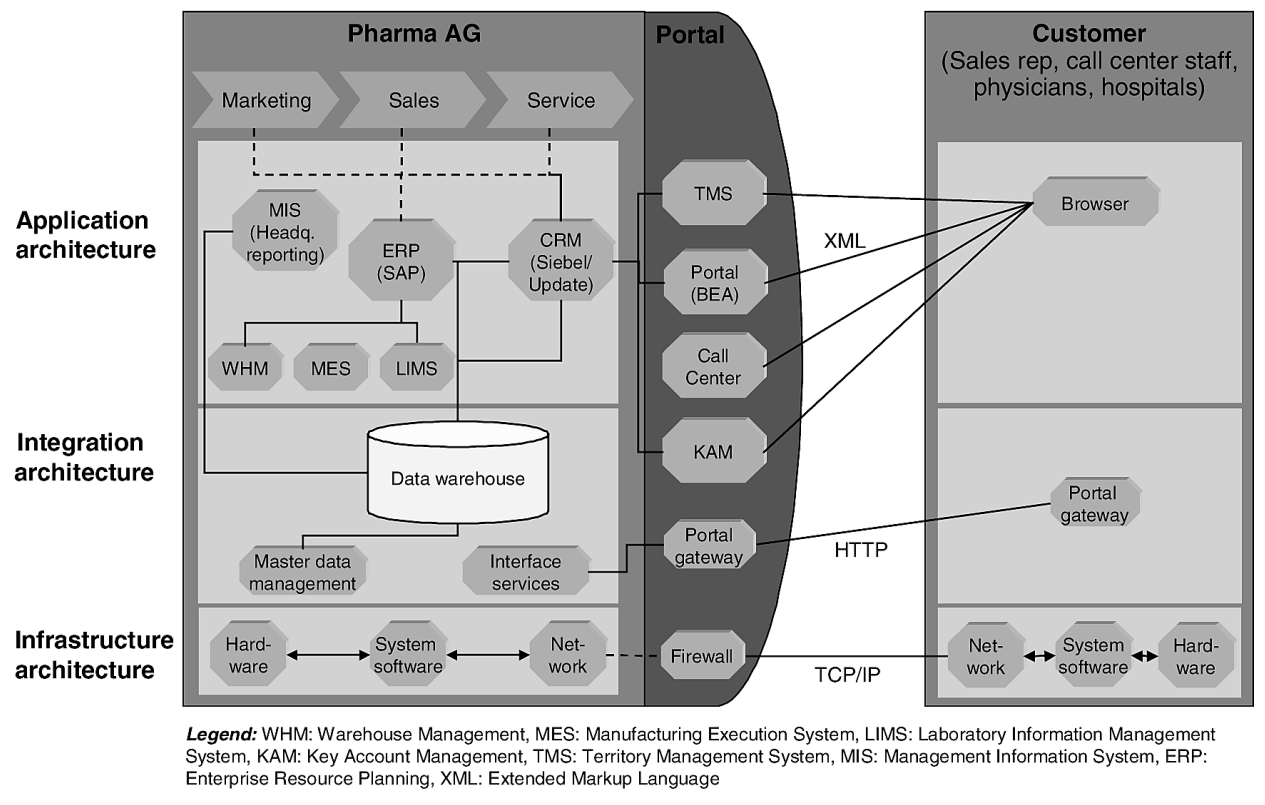

\section{Summary and outlook}

Deregulation, cost pressures, and electronic distribution channels are forcing pharma companies to adopt customer oriented strategies and to reflect the sustainability of their existing strategies. The limitations of currently used TMS and KAM show the need of implementing an integrated CRM solution based on a clearly defined architecture. Pharma companies face transformations on three levels. The business architecture supports the positioning regarding the target customer segments and electronic intermediaries. The process architecture identifies customer processes for each segment and derives portal services which can also be sourced from external web service providers. Finally, the system architecture reflects the organisational culture and enables interoperability across heterogeneous applications. Although CRM benefits are typically difficult to quantify, Pharma AG has already experienced benefits in two areas: 
- $\quad$ CRM benefits. Since the implications of CRM on additional revenues are difficult to quantify, Pharma AG focused on the efficiency of sales and marketing processes. For example, one branch office calculated an estimated increase of the sales force from 530 to 940 until 2005 due to the variety of new products. CRM is expected to save approx. 190 of the additional sales reps since only A and B customers will be visited regularly in future, while C and D customers will be referred to the portals for product detailing. Besides manpower cost such as expenses, samples, advertising material and tied-up assets (e.g. laptops) are reduced. In another branch a more targeted customer communication reduced the sales rep workload for a single product line by approx. 25,000 visits (to doctors who never prescribe) per year (plus the associated costs for advertising material, samples and expenses).

- Architecture benefits. Among the typical benefits of architectures are reduced redundancies which lead to reusable and interoperable solutions. For example, pre-configured portals for physicians can be implemented in multiple country organisations while development and maintenance skills are centralised in a dedicated organisation unit, the portal factory. Pharma AG has accelerated the portal development from 9-12 months to 2-3 months. Similar synergies are expected for the implementation of the CRM standard solutions Siebel and Update.

The implementation of the CRM architecture is the basis for exploiting further technological potentials. For example, the information in the CRM system is now only used to formulate individual marketing campaigns or to provide more effective support for field sales. Tools for analytical CRM help in systematically extracting information about customer requirements. Mobile technologies are another area that is monitored for improved sales force support. Using the architecture framework Pharma AG hopes to evaluate, position, and integrate these technologies at an early stage.

\section{References and Notes}

1 Products with annual revenues of USD 500 million or more [2].

2 David, C. (2000) 'Marketing to the consumer: perspectives from the pharmaceutical industry', Marketing Health Services, Vol. 21, No. 1, pp.4-11.

3 Sellers, L.J. (2001) 'Pharma's quantum shuffle', Pharmaceutical Executive, Vol. 21, No. 8, p.70.

4 Kalustian, J., Lombardi, B. and Fletcher, W. (2002) 'CRM checklist for success', Pharmaceutical Executive, Vol. 22, No. 2, pp.64-66.

5 Lin, B. and Huarng, F. (2000) 'Internet in the pharmaceutical industry: infrastructure issues', American Business Review, Vol. 18, No. 1, pp.101-106.

6 Porter, M.E. (2001) 'Strategy and the internet', Harvard Business Review, Vol. 79, No. 3, pp.63-78.

7 Rigby, D.K., Reichheld, F.F. and Schefter, P. (2002) 'Avoid the four perils of CRM', Harvard Business Review, Vol. 80, No. 2, pp.101-109.

8 Whyte, W.F. (1991) Participatory Action Research, Newbury Park: Sage Publications. 
9 Challener, C. (2000) 'Customer relationship management and R\&D are key for Pharma applications', Chemical Market Reporter, Vol. 258, No. 17, p.19.

10 Zabada, C., Singh, S. and Munchus, G. (2001) 'The role of information technology in enhancing patient satisfaction', British Journal of Clinical Governance, Vol. 6, No. 1, pp.9-16.

11 Bates, A. Bailey, E. and Rajyaguru, I. (2002) 'Navigating the e-detailing maze', International Journal of Medical Marketing, Vol. 2, No. 3, pp.255-262.

12 Breitstein, J. (2002) 'DTC in Europe?' Pharmaceutical Executive, Vol. 22, No. 1, pp.62-63.

13 Winer, R.S. (2001) 'A framework for customer relationship management', California Management Review, Vol. 43, No. 4, pp.89-105.

14 Hagemeier, D. (2002) The Case for Multichannel Pharmaceutical CRM, Stamford, CA: Gartner.

15 Ives, B. and Learmonth, G.P. (1984) 'The information system as a competitive weapon', Communications of the ACM, Vol. 27, No. 12, pp.1193-1201.

16 Österle, H. (1995) Business in the Information Age: Heading for New Processes, Berlin: Springer.

17 The business-to-government area was not analysed since it does not directly affect the sales process.

18 Junger, D. e-detailing: The Future of the Primary Care Salesforce? InPharm.com, http:// www.inpharm.com/netfocus/news/viewpoints/view_035.html, 20.04.

19 Burckhardt, J. Engler, C. and Salinas, L. (2001) Pharma-Markt Schweiz, Basel: Pharma Information.

20 Anonymous (1999) Pharma 2005: Marketing to the Individual, New York, NY: Pricewaterhouse Coopers.

21 Vamedis.net (www.vamedis.net) is a marketplace set up by manufacturers of medical appliances and consumables. The company merged with Global Healthcare Exchange (www.ghx.com) in 2002.

22 Nevins, R.L. and Pion, R.J. (2000) 'Telemedicine becomes a reality with web-enabled applications and net devices', in D.E. Goldstein (Eds.) E-Healthcare-Harness the Power of Internet e-Commerce \& e-Care, Maryland: Aspen Publishers, pp.189-210.

23 For the complementary nature of internet solutions see [6] and [24].

24 Gulaty, R. and Garino, J. (2000) 'Get the right mix of bricks \& clicks', Harvard Business Review, Vol. 78, No. 3, pp.107-114.

25 Österle, H. (2001) 'Enterprise in the information age', in H. Österle, E. Fleisch and R. Alt (Eds.) Business Networking: Shaping Collaboration Between Companies, Berlin: Springer, pp.17-53.

26 In Germany, for example, the price range between pharma companies and wholesalers is regulated. Only discounts, terms of delivery and payment dates are freely negotiable.

27 As described by Sleeper and Robins [28], the term web services covers a business and a technical perspective. The latter characterises an object oriented system architecture which uses standardised XML-based messages for programme calls and other parameters (SOAP), the functional description (WSDL) and their classification in a central repository (UDDI). This article concentrates on the business perspective.

28 Sleeper, B. and Robins, B. (2002) The Laws of Evolution: A Pragmatic Analysis of the Emerging Web Services Market, San Francisco, CA: The Stencil Group. 